the following reasons. First, it was not difficult to secure the cooperation of library users because the USF research center psychiatrists, psychologists, and other mental health practitioners are libraryoriented and very aware of rising journal costs. Second, because the research center library has a staff of four - one full-time professional, two fulltime paraprofessionals, and one graduate assistant-it was necessary to utilize a procedure that was not heavily labor-intensive; various ways of marking journals, distributing patron surveys, or direct observation would not have been feasible.

Once the choice was made, the following procedure was implemented. During the day, any journals that are found anywhere within the library are brought to the circulation desk. Available library staff records the usage for each journal, with tally marks on a weekly data collection sheet that lists all current journal subscriptions. The items are then placed on a reshelving cart. At the end of every month, the total of these weekly tally records is combined with interlibrary loan statistics and inserted into a Lotus 1-2-3 computer spreadsheet. Formulas automatically compute the usage for the year to date, and printouts are provided to any interested patron.

Administrators and department chairs regularly review the monthly journal usage, and these statistics serve a useful purpose. Combined with reports of periodical subscription increases supplied by the librarian and updates of the ongoing research projects of the Institute staff, journal usage statistics help to determine which subscriptions will be canceled and which ones added in the next fiscal year. There are no funding surprises, and there is no requirement for a written justification for a periodical budget increase from the librarian. Also, by involving faculty and staff in the project, they acquired a vested interest, and "the" library became "our" library. Unwittingly, the library staff made a positive contribution to public relations with library patrons. Indeed, perhaps this enhanced collegiality has been the most valued result of all.

By refining the data collection sheets and adding categories for the next fiscal year, the research center library staff plans to study additional aspects of periodical usage.

\title{
Access to serials: Local improvements may make a difference
}

\section{By David Trithart}

\author{
Reference Librarian \\ Potsdam College of SUNY
}

Every library has a limited list of serials to which it subscribes. Beyond that it relies on interlibrary loan or some other means to obtain articles for its patrons. Most libraries have seen the use of this service expand in recent years. The number of journals grows and the proportion represented in the local collection inexorably falls. It is commonly believed that the advent of indexes on $\mathrm{CD}$ will contribute to the demand for articles not in the local collection.

What alternative is there to increased reliance on borrowing or document delivery services? We determined to try to improve access to the journals we already receive. Like many libraries, we recently introduced compact disk indexes and have seen their use grow quickly. We also noticed that there remained a bottleneck in the search process. Checking the citations obtained so quickly from the $\mathrm{CD}$ had to be done manually in the library's serials list. The first remedy that occurred to us was to somehow match the journals on the $\mathrm{CD}$ with a list of those we receive, and have our titles highlighted or otherwise noted on the screen.

We have suggested this to CD producers, and there is some expressed interest, but nothing to show for it yet. Since we catalog our serials and shelve them by call number we would need to show, in addition to the holdings of a title, the call number. in theory this should be possible since we, like most libraries, have our serials and holdings in machine-readable form. The screen display for each citation could include local holdings information obtained from that list.

But this didn't seem to be an immediate possibility. A less automated approach was, however, within the range of our abilities. Using Microsoft Works (a simple, widely-used database program) on a Macintosh computer, we produced a database 
of all the periodicals to which we had subscribed since 1980. Holdings and call numbers were included for each title. For each index we noted those titles on our list which were covered by the index. The lists provided in the indexes themselves were supplemented with information taken from our serials control system (in this case SC350) which allowed us to search and display the 510 field of the MARC records for our serials. This information was displayed in a simple, single-line format in alphabetical order by periodical title.

This project took some time, but was made considerably simpler by having some of this information already on disk. The rest was added over the course of several months. The products have been some 11 index-specific lists that are kept on the consulting table beside the appropriate index. Rather than check citations against a large alphabet of titles, users can check a short list that pertains to just the index they are using. This is particularly useful at the CD indexes. The WilsonDisc indexes we have only extend back to the early 1980s, so the lists we produce are completely accurate as to our holdings of the journals indexed. Maintaining the lists has proven to be quite easy. Both staff and students agree that the time to produce the lists was well spent.

The interesting development is that our requests for interlibrary loans have decreased quite significantly for the twelve months since these lists were produced. This may be coincidental, but other libraries I have contacted do not report this trend. We may be able to attribute this decrease in more effective use of our own collection. The CD indexes make it easy to search multiple years of an index, and the lists we have produced enable users to quickly check which ones are here. Circulation of bound and unbound periodicals the past year showed a $15 \%$ increase compared to the average of the previous 4 years, and was $26 \%$ above the immediately prior year.

To see interlibrary loan going down at the same time that local circulation is on the rise does raise some questions. Users may be relying on articles several years old instead of requesting newer articles from journals we don't have. For most undergraduate research and paper-writing this is probably satisfactory. It just might be that some fairly simple efforts to improve access have contributed to this result.

\section{Section funding discussion}

\section{By Helen H. Spalding}

\author{
Associate Director of Libraries \\ University of Missouri-Kansas City
}

\begin{abstract}
ACRL's Budget and Finance Committee has been reviewing how ACRL sections are funded within the overall divisional budget and is now asking for your input. Nothing is inherently wrong with how sections are funded within the division, but with the current level of section participation, it may be a good time to look at current practice, inform the members, and document the funding structure.
\end{abstract}

In an effort to examine section funding strategies and formulate recommendations for keeping the current practice- or for trying one that may be more responsive to the priorities and needs of membership - the Budget and Finance Committee is inviting all members to attend an open hearing on section funding on Sunday, January 13, 1991, at the ALA Midwinter Meeting, from 8:00 p.m. to 10:00 p.m. (location to be announced). Your reaction to this article and feedback at the open hearing is crucial to the Committee's ability to determine if change is warranted, and if so, how it can be done in the best interests of the members.

Divisional dues are the only source of funds the Budget and Finance Committee has to support membership services, including Board support; statistics; advisory services; standards distribution; awards; committees; sections; chapters and discussion groups. When sections generate new activities (newsletters, for example) that require financial support, or when new sections are formed, their funding must come from this pool of membership dues. Unless membership dues are raised to cover new activities, section budgets must be weighed against other member activities.

Traditionally, the sixteen ACRL sections submit their annual budget requests, with justification based upon the Strategic Plan, by December 1 each year. Based upon the section's initiative, the current division budget, and the projected division budget, the Budget and Finance Committee rec- 